\title{
Cost of Intensive Care Treatment for Liver Disorders at Tertiary Care Level in India
}

\author{
Shankar Prinja ${ }^{1}$ Pankaj Bahuguna ${ }^{1}$ Ajay Duseja ${ }^{2}$ - Manmeet Kaur ${ }^{1}$. \\ Yogesh Kumar Chawla ${ }^{2}$
}

Published online: 14 July 2017

(c) The Author(s) 2017. This article is an open access publication

\begin{abstract}
Background Liver diseases contribute significantly to the health and economic burden globally. We undertook this study to assess the health system costs, out-of-pocket (OOP) expenditure and extent of financial risk protection associated with treatment of liver disorders in a tertiary care public sector hospital in India.

Methodology The present study was undertaken in an intensive care unit (ICU) of a tertiary care hospital in North India. It comprised an ICU and an HDU (high dependency unit). Bottom-up micro-costing was undertaken to assess the health system costs. Data on OOP expenditure and indirect costs were collected for 150 liver disorder patients admitted to the ICU or HDU from December 2013 to October 2014. Per-patient and per-bed-day costs of treatment were estimated from both health system and patient perspectives. Financial risk protection was assessed by computing prevalence of catastrophic health expenditure as a result of OOP expenditure.
\end{abstract}

Electronic supplementary material The online version of this article (doi:10.1007/s41669-017-0041-4) contains supplementary material, which is available to authorized users.

Shankar Prinja

shankarprinja@gmail.com

1 School of Public Health, Post Graduate Institute of Medical Education and Research, Chandigarh 160012, India

2 Department of Hepatology, Post Graduate Institute of Medical Education and Research, Chandigarh, India
Results In 2013-2014, health system costs per patient treated in the ICU and HDU were US\$2728 [Indian National Rupee (INR) 1,63,664] and US\$1966 (INR $1,17,985)$, respectively. The mean OOP expenditures for treatment in the ICU and HDU were US\$2372 (INR 1,42,297) and US\$1752 (INR 1,05,093), respectively. Indirect costs of hospitalization in ICU and HDU patients were US\$166 (INR 9952) and US\$182 (INR 10,903), respectively.

Conclusion Treatment of chronic liver disorders poses an economic challenge for both the health system and patients. There is a need to focus on prevention of liver disorders, and finding ways to treat patients without exposing their households to the catastrophic effect of OOP expenditure.

\section{Key Points for Decision Makers}

Significant evidence of the health burden and consequences of liver disorders exists in India.

There has been no evidence published of the significant economic implications which emerge alongside the rising burden of risk factors for liver disorders.

Our study reports the direct medical costs from both the health system and patient perspectives, as well as the indirect costs on account of lost productivity.

Our findings could also be used for setting reimbursement decisions for treatment of liver disorders in various publicly financed insurance schemes as well as assessing the cost effectiveness of related interventions. 


\section{Introduction}

Liver diseases contribute significantly to the global burden of mortality and morbidity [1, 2]. Globally, liver cirrhosis alone accounts for more than a million deaths, which is $2 \%$ of overall deaths, and 31 million disability-adjusted lifeyears (DALYs), which is $1.2 \%$ of total DALYs.

Along similar lines, liver disorders are widely prevalent in India. These represent a wide spectrum ranging from those with chronic infections, to those affected by alcohol consumption, and finally comprising the non-alcoholic fatty liver disorders. With over 40 million hepatitis B virus (HBV) carriers in India, the country falls into the intermediate level of HBV endemicity [3]. The population prevalence of $\mathrm{HBV}$ and hepatitis $\mathrm{C}$ virus (HCV) infection in India is 3.7 and $1 \%$, respectively. In the developed countries, dominant risk factors for chronic liver disease (CLD) include alcohol and HCV. On the other hand, HBV and $\mathrm{HCV}$ are responsible for the majority of CLDs in India [4]. Since 2007, alcohol has fast emerged as an important risk factor, and it constituted the leading cause of CLDrelated morbidity and mortality in India during 2010-2011 [4].

Liver disorders pose a significant economic challenge in terms of management of these chronic infections. In 2007, in the US, cirrhosis was graded as one of the leading causes of death. The estimated economic burden due to liver cirrhosis was significant, with the main cost of treatment ranging from US $\$ 14$ million to US $\$ 2$ billion, depending on disease etiology [5]. Treatment costs of morbidities related to $\mathrm{HCV}$ in ten European Union countries were estimated to be $€ 50$ million, and hence a significant burden on society. Similarly, €3 billion was reported to have been lost in Spain as a result of HCV over a 20-year time period [6].

Despite such a high economic burden, as evident from Western countries, there are no Indian estimates for the cost of treating liver disorders. In fact, there is very little evidence of cost of curative care in the public sector from a health-system perspective [7-11], and whatever is available is mostly for primary and secondary care [8-11]. The economic data becomes even scarcer for the tertiary care sector [7] and chronic diseases. Apart from significant economic implications for the health system, treatment of liver disorders leads to high out-of-pocket (OOP) expenditure for patients. This OOP expenditure in turn manifests as catastrophic spending by households which pushes them below the poverty line $[6,12]$. Treatment for liver disease is also likely to impose high OOP expenditure on account of its intensive resource requirement and chronic nature.

Hence, we undertook the present study to bridge this gap in the evidence base. Firstly, from a health system perspective, we estimated per-bed-day admission costs of intensive care treatment of liver diseases in a tertiary care hospital setting. Secondly, from patient perspective, we determine the OOP expenditure on treatment, the extent of financial risk protection in terms of catastrophic health expenditure (CHE), and mechanisms to cope with the OOP expenditure.

\section{Methodology}

\subsection{Study Setting}

We conducted this study in the Post Graduate Institute of Medical Education and Research (PGIMER), a tertiary care hospital, situated in the North Indian city of Chandigarh. With a total of 356 consultants and 2000 resident doctors, the hospital caters to an annual inpatient and outpatient attendance of 78,568 and 2,061,911, respectively [13].

The present cost analysis was undertaken in a specialized intensive care unit (ICU) for the treatment of liver disorders, under the Department of Hepatology. The ICU is broadly classified into two parts: the intensive care unit (ICU) and the high dependency unit (HDU). The criterion for this classification is based on the severity of patients with liver disorders, with more severe patients being admitted to the ICU. In addition to the HDU facilities, the ICU has ventilator and dialysis support, and endoscopic interventions for critical care required for more severe patients. Both the units have five beds each. A common pool of human resources was involved in provision of services in both ICU and HDU, supported by a laboratory and ultrasound and fibro-scan facility. These diagnostic facilities are utilized for the ICU (and HDU) patients along with the other liver disorder patients who consult the outpatient department and those admitted to general wards in the hospital. Besides this, the general diagnostic (pathological and radiological) facilities of the hospital are also used for the liver ICU patients. A total of 171 and 142 new admissions were treated in the ICU and HDU, respectively, during the year 2014.

\subsection{Data Collection}

\subsubsection{Health System Costs}

We adopted a bottom-up micro methodology to assess the health system costs. We collected data on health system resources used to provide patient care during a 1-year period from April 2013 to March 2014. The methodology for data collection comprised record reviews, physical inspection of facility, and staff interviews. The collected data included number of human resources (i.e. medical, 
paramedical staff, administrative, support staff, etc.), space in the building, numbers and types of equipment, other non-consumable items, diagnostic tests (laboratory and radiological), medicines, consumables and other overhead costs. Data was collected on the quantity of different resources being used exclusively for ICU or HDU patients, or in shared manner for both [Supplementary Appendix, Tables S1-S7, see electronic supplementary material (ESM)].

All resources were classified as recurrent or non-recurrent/capital resources. Recurrent costs included staff salaries, medicine and consumables, diagnostic tests and overheads costs (i.e. electricity, water consumption, laundry, dietetics, etc.). Non-recurrent or capital resources mainly comprised building or space, equipment (medical and non-medical) and furniture with a lifespan of $>1$ year. Price data was collected from the procurement department of the Institute [14]. For prices that were not available from the procurement department, we used the average market price from among the leading three manufacturers/suppliers, which was then adjusted based on a factor between market price and government procurement price. However, since the market prices are higher than the government procurement price, we adjusted the same using a scaling factor. This scaling factor was the average ratio of health system price and market price for other drugs and consumables, where prices were available from both the sources. All prices were adjusted to current values using gross domestic Product (GDP) deflators. Besides the data on quantity of resources utilized and their prices, we also collected data on number of patients treated during the same reference period, separately for the ICU and HDU. Face-to-face interviews of staff members (faculty, resident doctors, nursing staff, support and administrative staff) were conducted to elicit time spent on different activities during a 1 -week period.

\subsubsection{Out-of-Pocket Expenditure}

For OOP expenditure, all new patients admitted to the liver ICU during the period from December 2013 to October 2014 were recruited. Written informed consent of the patient or accompanying caregiver (if patient was not conscious) was obtained. Data was collected at the time of recruitment, followed by a daily interview to elicit OOP expenditure incurred for treatment over the last $24 \mathrm{~h}$. This was continued on a daily basis till the discharge or final outcome of the patient. OOP expenditure was elicited for hospital charges, medicines, laboratory tests, procedure or surgery, transportation, boarding/lodging and meals of attendants with patient, and lastly informal payments (if any).

Secondly, we collected data on socio-demographic characteristics including household consumption expenditure (food and non-food). Patients were also interviewed to elicit mechanisms to cope with the OOP expenditure for treatment. Lastly, in order to assess indirect costs owing to lost productivity, both for patients and caregivers, we also collected data on time spent by patient on routine activities (i.e. professional work, household activities, childcare, voluntary and social activities, physical or leisure activities, etc.) in the days of good health before his/her admission to ICU or HDU.

\subsubsection{Follow-Up Patient Interviews}

We also followed up the patients telephonically at Month 1,3 and 6 from the date of discharge to record OOP expenditure for further treatment (if any) and the survival status of the patient. Any OOP expenditure for out-patient or in-patient treatment after discharge from any health facility was assessed. Data on OOP expenditure collected at each follow-up was mutually exclusive in nature (i.e. specifically for that period). For example, at Month 1 follow-up, data on OOP expenditure was collected from discharge date to completion of Month 1 . The same occurred for Month 1 to Month 3 (2-month period) at Month 3 follow-up, and for Month 3 to Month 6 (3-month period) at the Month 6 follow-up.

\subsection{Data Analysis}

\subsubsection{Health System Costs}

Data was analysed using Statistical Package for Social Sciences (SPSS) version 21 and MS Excel. The cost of space for the hepatology ICU was estimated by applying rental price for the area. Costs of various equipment (and furniture) available in the ICU and HDU were annualized based on their average useful life and discounting to arrive at an equivalent uniform annual cost. An average discount rate of $3 \%$ was used to compute the annualization factor [15]. Replacement costs of equipment were preferred over original costs. These replacement costs were computed by adjusting original costs using the consumer price index. All the costs were converted to US dollars (US\$) for comparability at a wider level at the rate of US $\$ 1$ equal to 60 Indian National Rupees (INR) [16]. Overall cost of service provision was estimated. Finally, all the cost estimates were converted to 2014 prices to adjust for inflation, applying a discounting factor of $3 \%$ per year.

2.3.1.1 Apportioning Statistics Appropriate apportioning statistics were used to allocate shared or joint resources to the ICU and HDU. Firstly, the shared cost of human resources was apportioned to ICU care, non-ICU inpatient care, outpatient care and other general teaching, research 
and administrative work. Interviews with various staff working with the ICU unit were done to collect the data on time allocation patterns. We interviewed different categories of personnel involved in ICU services, which mainly included consultants, resident doctors, nurses and technicians to capture data on work flow patterns, and time spent per activity during the previous week. Proportion of time spent on each activity was used as the basis for apportioning the shared human resource costs to various cost centres and functional activities. Data obtained through these interviews was used for apportioning the share cost of human resource.

Secondly, costs of shared building/space (i.e. laboratory, waiting area, discussion room, doctor's room, etc.), equipment and overheads were apportioned among the ICU and HDU on the basis of proportion of bed-days of ICU and HDU patients in a year. Costs of medicines and consumables could not simply be apportioned based on inpatient bed-days of admission in the ICU and HDU, as these are dependent on the patients' severity of illness. Hence, we apportioned the cost of medicines and consumables being used jointly for HDU and ICU patients, based on a ratio of average OOP cost of medicines for ICU and HDU patients. This was considered appropriate as there were no prioritization criteria used for issue of medicines and consumables between the ICU and HDU.

2.3.1.2 Unit Costs Per-patient and per-bed-day costs of treatment were estimated for both ICU and HDU patients.

\subsubsection{Out-of Pocket Expenditure}

We estimated the mean and standard error of OOP expenditure at the overall level and by socio-demographic characteristics of individuals, and also by diagnostic category. Patients with liver disorders were classified into five categories: acute viral hepatitis/acute liver failure, cirrhosis (includes alcohol-related cirrhosis, HBV, HCV, autoimmune hepatitis (AIH), non-alcoholic steatohepatitis and others), acute-on-chronic liver failure (ACLF), hepatocellular carcinoma (HCC) and extrahepatic biliary tract obstruction (EHBO).

\subsubsection{Financial Risk Protection}

Financial risk protection is one of the components of universal health coverage (UHC) [17]. It ensures that the population of a state/country can access quality healthcare services at the time of need without any financial hardship [17-19]. In general, there are two methods to measure financial risk protection, which include prevalence of $\mathrm{CHE}$ and impoverishment due to OOP expenditure [19-21]. We computed $\mathrm{CHE}$ to measure financial risk protection, which is defined as OOP spending for healthcare exceeding a given threshold of households' paying capacity [19-21]. More specifically, it implies any OOP expenditure on health which exceeds $40 \%$ of household non-food consumption expenditure.

There are two thresholds available in the literature to estimate the prevalence of CHE based on households' paying capacity. The first approach considers any health expenditure exceeding $10 \%$ of a household's total consumption expenditure as catastrophic, while the second approach considers $40 \%$ of non-subsistence expenditure (or non-food related) as the threshold. The second approach is considered more appropriate from an equity perspective, and hence we adopted the latter [19-22]. To compute prevalence of $\mathrm{CHE}$, OOP expenditure that was in excess of $40 \%$ of household non-food consumption expenditure was considered as catastrophic. In addition, we undertook a sensitivity analysis by computing prevalence of $\mathrm{CHE}$ based on the $10 \%$ of total expenditure cut-off. Lastly, we also analysed the coping mechanisms for OOP expenditure by calculating the percentage of OOP expenditure which was met through salaries/savings, borrowing without interest, borrowing with interest, selling of assets, or any form of health insurance.

\subsubsection{Indirect Costs}

Data collected on indirect costs (i.e. productivity loss of patients/caregivers due to hospitalization) was analysed using a human capital (HC) approach. There are two broad approaches for valuing productivity loss due to illness, $\mathrm{HC}$ and friction cost (FC) $[23,24]$. In the $\mathrm{HC}$ approach, income and fringe benefits of an employee (or market wage) are considered as a proxy of his productivity loss due to illness, while the FC approach considers replacement cost of an employee to carry out his work. Although the FC method measures the productivity loss in a more realistic way, it is data intensive which introduces significant uncertainties. On the other hand, $\mathrm{HC}$ demands less data and is amenable for easy communication [23, 24]. Hence, we used the HC approach for analysis of indirect cost data in our study.

\subsubsection{Estimates}

All the estimates for health system costs, OOP expenditure and indirect costs are reported in both INR and US\$. Also, 95\% confidence intervals (CI) are reported for OOP expenditure and indirect costs along with their base estimates. 


\section{Results}

\subsection{Sample Characteristics}

A total of 150 patients were recruited for estimation of OOP expenditure, of which 85 and 65 were from HDU and ICU, respectively. Of all patients, males represented nearly $75 \%$ in the ICU and nearly $62 \%$ in the HDU. More than $80 \%$ of patients both in the ICU and HDU were aged $>30$ years and almost $45 \%$ were aged $>50$ years. Mean length of stay for ICU and HDU patients was 13 and 11 days, respectively. Around 72 and $87 \%$ of patients were discharged alive from the ICU and HDU, respectively (Table 1). Almost $68 \%$ of the patients admitted to the hepatology ICU had some form of cirrhosis, followed by $13.5 \%$ with EHBO and ACLF, $10.8 \%$ with hepatocellular carcinoma and $7.4 \%$ with acute viral hepatitis/acute liver failure.

\subsection{Health System Costs}

The annual cost incurred by the health system for ICU and HDU care in the year 2014 was US $\$ 386,199$ (INR231, INR71,939) and US\$336,651 (INR201, INR99,069), respectively (Table 2). For the ICU and HDU, the share of personnel costs was highest $(37 \%$ ICU and $43 \% \mathrm{HDU}$ ), followed by physical infrastructure (27\% ICU and 31\% HDU) and diagnostics (20\% ICU and $12 \%$ HDU). Per-patient treated and per-bed-day admission cost for treatment in the ICU were US\$2728 (INR163,664) and US\$212 (INR12,697), respectively. Similarly, the cost of treatment was US\$1966 (INR117,985) per patient and US\$185 (INR11,068) per bed-day in the HDU (Table 2).

\subsection{Out-of-Pocket Expenditures}

The mean OOP expenditures for treatment in the ICU and HDU were US $\$ 2372$ (95\% CI 1881-2862) and US $\$ 1752$ (95\% CI 1329-2174), respectively (Table 3). Medicines accounted for a major share of OOP expenditure-85 and 79\% among ICU and HDU patients, respectively (Fig. 1). Mean OOP expenditures per patient bed-day in the ICU and HDU were US\$220 (INR13,194) and US\$151 (INR9088), respectively. Salary or savings was the predominant source of finance to meet the OOP expenditure among 51 and $57 \%$ patients treated in the ICU and HDU, respectively (Fig. 2). Mean OOP expenditure was relatively higher in patients diagnosed with ACLF [US $\$ 3170$ (INR190,202)], followed by cirrhosis and acute viral hepatitis/acute liver failure [US\$2131 (INR127,899) and US\$1928 (INR115,668), respectively].
Using a $40 \%$ threshold for CHE, we found that $87 \%$ of patients admitted to the ICU incurred CHE, while its prevalence was $71 \%$ for HDU patients (Table 3). Prevalence of CHE in our study did not vary much when we used $10 \%$ of total consumption expenditure (i.e. 98 and $84 \%$ for the ICU and HDU, respectively). This signifies that the conclusion is robust regarding choice of thresholds used to define catastrophic expenditure. The mean indirect cost estimation for ICU and HDU patients was US\$166 (95\% CI 117-215) and US\$182 (95\% CI 139-224), respectively (Table 4).

\subsubsection{Follow-Up}

Out of patients eligible for Month 1, 3 and 6 follow-ups, approximately $95 \%$ were followed up to record the data on post-hospitalization OOP expenditure (Supplementary Appendix, Fig. S1, see ESM). Mean OOP expenditures for patients 1 month after discharge from the ICU and HDU were US\$366 (95\% CI 178-554) and US\$977 (95\% CI 0-2153), respectively. Mean OOP expenditures at Month 3 follow-up, which reflected a 2-month period, were US\$894 (95\% CI 59-1729) and US\$635 (95\% CI 286-985) for ICU and HDU patients, respectively, and at Month 6 follow-up, for a period of 3 months, they were US\$498 (95\% CI 143-778) and US\$568 (95\% CI 166-893) for ICU and HDU patients, respectively.

\section{Discussion}

\subsection{Summary of Study Findings}

We undertook this study to assess the health system costs and OOP expenditure on account of tertiary care intensive treatment for liver disorders in India. Overall, we found that the health system cost per patient treated and per bedday admission to the ICU were US\$2728 (95\% CI 2580-3125) and US\$212 (95\% CI 200-242), respectively. Similarly, the cost of treatment was US\$1966 (95\% CI 1860-2253) per patient and US\$185 (95\% CI 174-211) per bed-day in the HDU. From the patients' perspective, the treatment of liver disorders incurred an OOP expenditure of US\$2372 (95\% CI 1881-2862) and US\$1752 (95\% CI 1329-2174) in the ICU and HDU, respectively. All patients admitted to the ICU, and $88 \%$ of those admitted to the HDU, experienced catastrophic expenditures. Of the total hospitalized patients, $29 \%$ had to borrow money to pay for treatment costs.

We found that the OOP expenditure during the period immediately after discharge was higher than later months. This is reflected in a higher OOP expenditure from 1 to 
Table 1 Characteristics of liver disorder patients admitted to the intensive care unit of a tertiary care hospital in India

\begin{tabular}{|c|c|c|c|c|c|c|}
\hline \multirow[t]{2}{*}{ Characteristics } & \multicolumn{2}{|c|}{ ICU } & \multicolumn{2}{|c|}{ HDU } & \multicolumn{2}{|c|}{ Total } \\
\hline & $N$ & $\%$ & $N$ & $\%$ & $N$ & $\%$ \\
\hline \multicolumn{7}{|l|}{ Gender } \\
\hline Male & 49 & 75.4 & 53 & 62.4 & 102 & 68.0 \\
\hline Female & 16 & 24.6 & 32 & 37.6 & 48 & 32.0 \\
\hline Total & 65 & 100 & 85 & 100 & 150 & 100 \\
\hline \multicolumn{7}{|l|}{ Age group } \\
\hline$<30$ years & 10 & 15.4 & 14 & 16.5 & 24 & 16 \\
\hline $31-50$ years & 25 & 38.5 & 31 & 36.5 & 56 & 37.3 \\
\hline$>50$ years & 30 & 46.2 & 40 & 47.1 & 70 & 46.7 \\
\hline Total & 65 & 100 & 85 & 100 & 150 & 100 \\
\hline \multicolumn{7}{|l|}{ Locality } \\
\hline Urban & 31 & 47.7 & 53 & 62.4 & 84 & 56 \\
\hline Slum & 2 & 3.1 & 3 & 3.5 & 5 & 3.3 \\
\hline Rural & 32 & 49.2 & 29 & 34.1 & 61 & 40.7 \\
\hline Total & 65 & 100 & 85 & 100 & 150 & 100 \\
\hline \multicolumn{7}{|l|}{ Education } \\
\hline Illiterate & 5 & 7.7 & 4 & 4.7 & 9 & 6.0 \\
\hline$<8$ th standard & 17 & 26.2 & 13 & 15.3 & 30 & 20.0 \\
\hline 8th-12th standard & 25 & 38.5 & 30 & 35.3 & 55 & 36.7 \\
\hline Graduate and above & 18 & 28 & 38 & 44.7 & 56 & 37 \\
\hline Total & 65 & 100 & 85 & 100 & 150 & 100 \\
\hline \multicolumn{7}{|l|}{ Occupation } \\
\hline Labourer & 8 & 12.3 & 7 & 8.2 & 15 & 10.0 \\
\hline Self-employed & 9 & 13.8 & 21 & 24.7 & 30 & 20.0 \\
\hline Unemployed & 21 & 32.3 & 33 & 38.8 & 54 & 36.0 \\
\hline Salaried & 27 & 41.5 & 24 & 28.2 & 51 & 34.0 \\
\hline Total & 65 & 100 & 85 & 100 & 150 & 100 \\
\hline \multicolumn{7}{|l|}{ Marital } \\
\hline Unmarried & 8 & 12.3 & 8 & 9.4 & 16 & 10.7 \\
\hline Married & 57 & 87.7 & 77 & 90.6 & 134 & 89.3 \\
\hline Total & 65 & 100 & 85 & 100 & 150 & 100 \\
\hline \multicolumn{7}{|l|}{ Wealth status } \\
\hline Poorest & 12 & 18.5 & 18 & 21.2 & 30 & 20 \\
\hline Poor & 12 & 18.5 & 17 & 20 & 29 & 19.3 \\
\hline Middle & 17 & 26.2 & 13 & 15.3 & 30 & 20 \\
\hline Rich & 14 & 21.5 & 17 & 20 & 31 & 20.7 \\
\hline Richest & 10 & 15.4 & 20 & 23.5 & 30 & 20 \\
\hline Total & 65 & 100 & 85 & 100 & 150 & 100 \\
\hline \multicolumn{7}{|l|}{ Duration of stay } \\
\hline$<3$ days & 11 & 16.9 & 21 & 24.7 & 32 & 21.3 \\
\hline $3-10$ days & 20 & 30.8 & 30 & 35.3 & 50 & 33.3 \\
\hline$>10$ days & 34 & 52.3 & 34 & 40.0 & 68 & 45.3 \\
\hline Total & 65 & 100 & 85 & 100 & 150 & 100 \\
\hline \multicolumn{7}{|l|}{ Outcome at discharge } \\
\hline Dead & 18 & 27.7 & 11 & 12.9 & 29 & 19.3 \\
\hline Alive & 47 & 72.3 & 74 & 87.1 & 121 & 80.7 \\
\hline Total & 65 & 100 & 85 & 100 & 150 & 100 \\
\hline
\end{tabular}

$H D U$ high dependency unit, $I C U$ intensive care unit
3 months following discharge, as compared with 4-6 months after discharge. This could be related to a relative improvement in patients' condition in subsequent months and hence a lesser need for more intense medication.

We acknowledge that there are significant variations in the healthcare infrastructure across the different states of India, as well as costs of resources which are used for delivery of services. Further, we estimated the cost of delivering treatment in one large tertiary care hospital. We chose this hospital as the treatment for most chronic liver disorders is usually not provided in secondary level hospitals and is available in similar tertiary care teaching hospitals only. However, all these factors may limit the extent of the generalizability of our cost estimates to the whole of India. We recommend undertaking a study incorporating a variety of geographic settings and levels of care in India to improve the generalizability of results.

\subsection{Financial Risk Protection: Current Status}

In general, In India there is a high prevalence of CHE. Some community-based research studies reported the prevalence of CHE for any kind of illness in the range of $30-56 \%[19,22,25,26]$. On the other hand, prevalence of CHE is extremely high in diseases requiring intensive care like chronic liver disorders, cancers, acute coronary syndrome, etc. One North Indian study reported the prevalence of CHE among households with a family member suffering from breast cancer to be $84 \%$ [27]. Similarly, a study done for the Asian region depicted that prevalence of CHE among households with an acute coronary syndrome event in India was more (i.e. $60 \%$ among the uninsured population) compared with other Asian countries like Malaysia, Thailand, Singapore, Vietnam, etc. [28]. Moreover, specifically in the Indian context where the income disparities are high, even a small amount of OOP expenditure becomes catastrophic for low-income segments of society [19, 26, 29]. Hence, our study findings are in concordance with the literature when specifically compared to other severe diseases requiring intensive care.

\subsection{Policy Implication: Prevention of Liver Disorders}

Our results have significant policy implications. Policy discourse in India is gradually building towards universal provision of healthcare services [30]. How the care provision will be organized is debatable; however, most policy documents recommend greater reliance on a tax-funded system of financing. In terms of provisioning of healthcare services, both models of publicly delivered healthcare services and purchasing of healthcare services through 
Table 2 Health system costs of treatment of liver disorder patients in the intensive care unit of a tertiary care hospital in India

\begin{tabular}{lcc}
\hline Health system costs & ICU US\$ (INR) & HDU US\$ (INR) \\
\hline Annual costs & & \\
Personnel & $143,402(8,604,123)$ & $143,402(8,604,123)$ \\
Equipment & $30,526(1,831,542)$ & $20,764(1,245,861)$ \\
Laboratory tests & $76,514(4,590,849)$ & $38,910(2,334,601)$ \\
Medicines and consumables & $6945(416,719)$ & $4763(285,778)$ \\
Stationary & $2973(178,371)$ & $2973(178,371)$ \\
Physical infrastructure & $104,760(6,285,600)$ & $104,760(6,285,600)$ \\
Utilities/overheads & $21,079(1,264,735)$ & $21,079(1,264,735)$ \\
Total & $386,199(23,171,939)$ & $336,651(20,199,069)$ \\
Unit costs & & $1966(117,985)$ \\
Cost per patient & $2728(163,664)$ & $185(11,068)$ \\
Cost per bed-day & $212(12,697)$ & \\
\hline
\end{tabular}

Conversion rate: $\$$ US1 $=$ INR60

$H D U$ high dependency unit, ICU intensive care unit, INR Indian National Rupee, US\$ United States dollar publicly financed health insurance schemes are evident [31]. The increasing incidence of liver disease and its risk factors $[32,33]$ highlights that prevention of liver disorders and their risk factors is likely to be a more cost-effective action and has to remain the mainstay of the policy. In terms of preventive actions, HBV vaccination remains a cornerstone.

In general, the most cost-effective vaccination strategy is usually determined by the endemicity of disease, the ease of implementing a vaccination programme with high coverage, the efficacy of vaccination, and the infectiousness of the causative agent [34]. From an Indian viewpoint, a pentavalent vaccine that includes HBV has been reported to be very cost effective with an incremental cost of US\$277 per disability-adjusted life-year (DALY) averted [35]. As per the Government of India's latest policy, HBV is given as part of a pentavalent vaccine that comprises diphtheria, pertussis and tetanus (DPT), haemophilus influenza type ' $b$ ' (Hib) and HBV. The National Technical Advisory Group on Immunization (NTAGI) in India recommended the introduction of the pentavalent vaccine in the Universal Immunization Program (UIP) in 2008, which was subsequently launched in 2011 in two South Indian states $[36,37]$. This has now been extended to children in several other states also. However, the coverage of this vaccine remains very low as per recent estimates [38], and hence needs strengthening for effective protection. Further, the Government of India also recommends a birth dose of HBV for all institutional births, which needs to be universalized.

The major preventive strategy for HCV remains controlling nosocomial exposure (i.e. blood screening, safe injection, and infection control) and reducing high-risk behaviours (i.e. intravenous drug use) [39]. Implementation of safe nosocomial practices reduces HCV transmission, but usually comes at a high cost of implementation that exceeds the fiscal ability of low-income countries [39, 40]. However, there have been recent instances of HCV outbreaks in India which have resulted from unsafe injection practices by unqualified practitioners and quack doctors [41]. Use of auto-disable syringes is one of the strategies to prevent re-use and its associated infections. An HCV seroprevalence of as high as $71 \%$ has been reported among injection drug users (IDUs) in North-East India [42]. In India, an Opioid Substitution Therapy (OST) strategy for IDUs was introduced by the Government of India under the National AIDS Control Program (NACP). Under OST, opiate-dependant persons are made to shift to orally administered opiates such as buprenorphine and methadone, replacing illicit drug use [43]. Accounting for the social costs, OST therapy using buprenorphine has been shown to have higher benefits at lower costs than no treatment [44].

The third set of preventive interventions, besides those against $\mathrm{HBV}$ and $\mathrm{HCV}$, are those directed against alcohol consumption and its health effects. It is evident that alcohol consumption leads to liver cirrhosis and related mortality and hence, policies and procedures intended to restrict alcohol consumption are likely to benefit [44-47]. These policies include those which are targeted to a specific population group such as school-based campaigns. Alternatively, these could be general public education campaigns on harmful effects of alcohol. Similarly, those at risk for alcoholism could also be targeted for counselling. Stringent alcohol purchase laws, government monopolies on alcohol, restrictions on alcohol marketing campaigns, and increased taxes on alcohol have all been shown to have positive effects on reduction in alcohol consumption [48]. 
Table 3 Direct costs (INR) as out-of-pocket expenditure and financial risk protection for treatment of liver disorder patients in the intensive care unit of a tertiary care hospital in India

\begin{tabular}{|c|c|c|c|c|c|c|c|c|c|c|}
\hline \multirow[t]{3}{*}{ Characteristic } & \multirow{2}{*}{\multicolumn{2}{|c|}{ ICU US\$ (INR) }} & \multirow{2}{*}{\multicolumn{2}{|c|}{ HDU US\$ (INR) }} & \multicolumn{6}{|c|}{ Catastrophic health expenditure (\%) } \\
\hline & & & & & \multicolumn{2}{|c|}{ ICU } & \multicolumn{2}{|c|}{ HDU } & \multicolumn{2}{|c|}{ Total } \\
\hline & Mean & SE & Mean & SE & $N$ & $\%$ & $N$ & $\%$ & $N$ & $\%$ \\
\hline \multicolumn{11}{|l|}{ Age group } \\
\hline$<30$ years & $3179(190,723)$ & $1006(60,336)$ & $1319(79,158)$ & $430(25,798)$ & 9 & 90 & 10 & 77 & 19 & 83 \\
\hline $31-50$ years & $1947(116,834)$ & $329(19,765)$ & $2188(131,260)$ & $407(24,395)$ & 19 & 76 & 20 & 71 & 39 & 74 \\
\hline$>50$ years & $2456(147,374)$ & $328(19,655)$ & $1565(93,891)$ & $327(19,635)$ & 25 & 96 & 27 & 69 & 52 & 80 \\
\hline Total & $2372(142,297)$ & $250(15,021)$ & $1752(105,093)$ & $216(12,939)$ & 53 & 87 & 57 & 71 & 110 & 78 \\
\hline \multicolumn{11}{|l|}{ Gender } \\
\hline Male & $2390(143,424)$ & $318(19,082)$ & $2120(127,221)$ & $289(17,315)$ & 38 & 83 & 40 & 80 & 78 & 81 \\
\hline Female & $2314(138,844)$ & $308(18,473)$ & $1141(68,444)$ & $290(17,395)$ & 15 & 100 & 17 & 57 & 32 & 71 \\
\hline Total & $2372(142,297)$ & $250(15,021)$ & $1752(105,093)$ & $216(12,939)$ & 53 & 87 & 57 & 71 & 110 & 78 \\
\hline \multicolumn{11}{|l|}{ Locality } \\
\hline Urban & $2331(139,830)$ & $376(22,579)$ & $1710(102,588)$ & $273(16,353)$ & 24 & 86 & 34 & 69 & 58 & 75 \\
\hline Slum & $2844(170,668)$ & $2364(141,868)$ & $1133(67,986)$ & $274(16,425)$ & 2 & 100 & 3 & 100 & 5 & 100 \\
\hline Rural & $2382(142,914)$ & $344(20,634)$ & $1892(113,509)$ & $392(23,549)$ & 27 & 87 & 20 & 71 & 47 & 80 \\
\hline Total & $2372(142,297)$ & $250(15,021)$ & $1752(105,093)$ & $216(12,939)$ & 53 & 87 & 57 & 71 & 110 & 78 \\
\hline \multicolumn{11}{|l|}{ Education } \\
\hline Illiterate & $3267(196,037)$ & $616(36,956)$ & $1123(67,400)$ & $638(38,298)$ & 5 & 100 & 2 & 50 & 7 & 78 \\
\hline$<8$ th standard & $2489(149,318)$ & $573(34,376)$ & $2905(174,283)$ & $532(31,943)$ & 14 & 88 & 13 & 100 & 27 & 93 \\
\hline 8th-12th standard & $2595(155,691)$ & $405(24,297)$ & $1576(94,550)$ & $349(20,963)$ & 21 & 95 & 23 & 79 & 44 & 86 \\
\hline Graduate and above & $1702(102,136)$ & $412(24,709)$ & $1562(93,714)$ & $333(19,960)$ & 13 & 72 & 19 & 56 & 32 & 62 \\
\hline Total & $2372(142,297)$ & $250(15,021)$ & $1752(105,093)$ & $216(12,939)$ & 53 & 87 & 57 & 71 & 110 & 78 \\
\hline \multicolumn{11}{|l|}{ Occupation } \\
\hline Labourer & $1811(108,666)$ & $694(41,666)$ & $3330(199,786)$ & $778(46,683)$ & 6 & 75 & 6 & 100 & 12 & 86 \\
\hline Self-employed & $1685(101,082)$ & $353(21,201)$ & $2302(138,113)$ & $485(29,099)$ & 6 & 86 & 17 & 89 & 23 & 88 \\
\hline Unemployed & $3338(200,258)$ & $512(30,698)$ & $1219(73,147)$ & $285(17,113)$ & 20 & 100 & 21 & 66 & 41 & 79 \\
\hline Salaried & $2015(120,919)$ & $348(20,877)$ & $1542(92,507)$ & $399(23,920)$ & 21 & 81 & 13 & 57 & 34 & 69 \\
\hline Total & $2372(142,297)$ & $250(15,021)$ & $1752(105,093)$ & $216(12,939)$ & 53 & 87 & 57 & 71 & 110 & 78 \\
\hline \multicolumn{11}{|l|}{ Marital } \\
\hline Unmarried & $3504(210,261)$ & $1088(65,265)$ & $1267(76,011)$ & $471(28,271)$ & 8 & 100 & 5 & 63 & 13 & 81 \\
\hline Married & $2213(132,758)$ & $239(14,357)$ & $1802(108,114)$ & $233(13,977)$ & 45 & 85 & 52 & 72 & 97 & 78 \\
\hline Total & $2372(142,297)$ & $250(15,021)$ & $1752(105,093)$ & $216(12,939)$ & 53 & 87 & 57 & 71 & 110 & 78 \\
\hline \multicolumn{11}{|l|}{ Wealth status } \\
\hline Poorest & $2739(164,368)$ & $585(35,075)$ & $1289(77,341)$ & $403(24,151)$ & 8 & 100 & 9 & 69 & 17 & 81 \\
\hline Poor & $1818(109,103)$ & $499(29,946)$ & $2030(121,781)$ & $551(33,078)$ & 11 & 92 & 15 & 88 & 26 & 90 \\
\hline Middle & $2767(166,005)$ & $680(40,795)$ & $3016(180,956)$ & $732(43,924)$ & 16 & 94 & 12 & 92 & 28 & 93 \\
\hline Rich & $2459(147,568)$ & $415(24,878)$ & $1351(81,058)$ & $289(17,321)$ & 12 & 86 & 11 & 65 & 23 & 74 \\
\hline Richest & $1799(107,960)$ & $399(23,966)$ & $1450(87,004)$ & $407(24,439)$ & 6 & 60 & 10 & 50 & 16 & 53 \\
\hline Total & $2372(142,297)$ & $250(15,021)$ & $1752(105,093)$ & $216(12,939)$ & 53 & 87 & 57 & 71 & 110 & 78 \\
\hline \multicolumn{11}{|l|}{ Duration of stay } \\
\hline$<3$ days & $692(41,495)$ & $65(3923)$ & $235(14,100)$ & 47 (2797) & 9 & 82 & 10 & 53 & 19 & 95 \\
\hline 3-10 days & $1284(77,025)$ & $173(10,409)$ & $998(59,909)$ & $120(7225)$ & 16 & 80 & 21 & 70 & 37 & 74 \\
\hline$>10$ days & $3555(213,304)$ & $361(21,679)$ & $3353(201,163)$ & $385(23,082)$ & 28 & 93 & 26 & 84 & 54 & 89 \\
\hline Total & $2372(142,297)$ & $250(15,021)$ & $1752(105,093)$ & $216(12,939)$ & 53 & 87 & 57 & 71 & 110 & 78 \\
\hline \multicolumn{11}{|l|}{ Outcome at discharge } \\
\hline Dead & $2128(127,651)$ & $272(16,308)$ & $3553(213,176)$ & $761(45,636)$ & 13 & 87 & 10 & 100 & 23 & 92 \\
\hline Alive & $2465(147,906)$ & $331(19,850)$ & $1484(89,027)$ & $205(12,311)$ & 40 & 87 & 47 & 67 & 87 & 75 \\
\hline Total & $2372(142,297)$ & $250(15,021)$ & $1752(105,093)$ & $216(12,939)$ & 53 & 87 & 57 & 71 & 110 & 78 \\
\hline
\end{tabular}

Conversion rate: \$US1 = INR60

$H D U$ high dependency unit, ICU intensive care unit, INR Indian National Rupee, SE standard error of the mean, US\$ United States dollar 


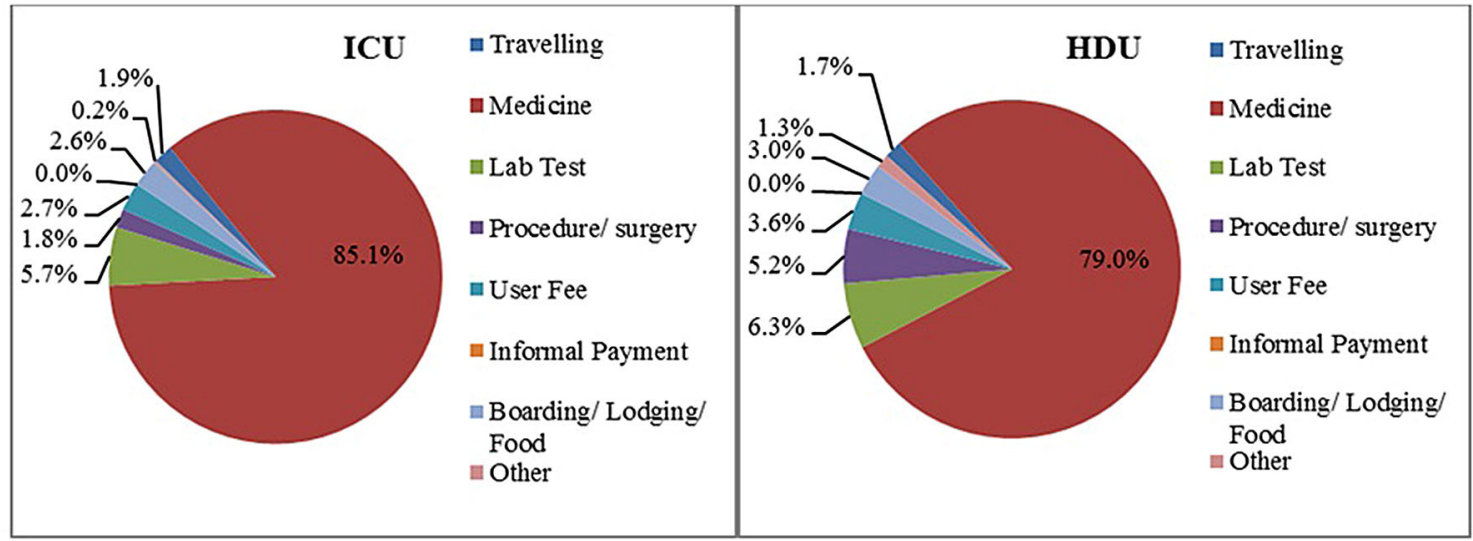

Fig. 1 Determinants (\%) of out-of-pocket expenditure for treatment of liver disorders in an intensive care unit in India. $H D U$ high dependency unit, $I C U$ intensive care unit

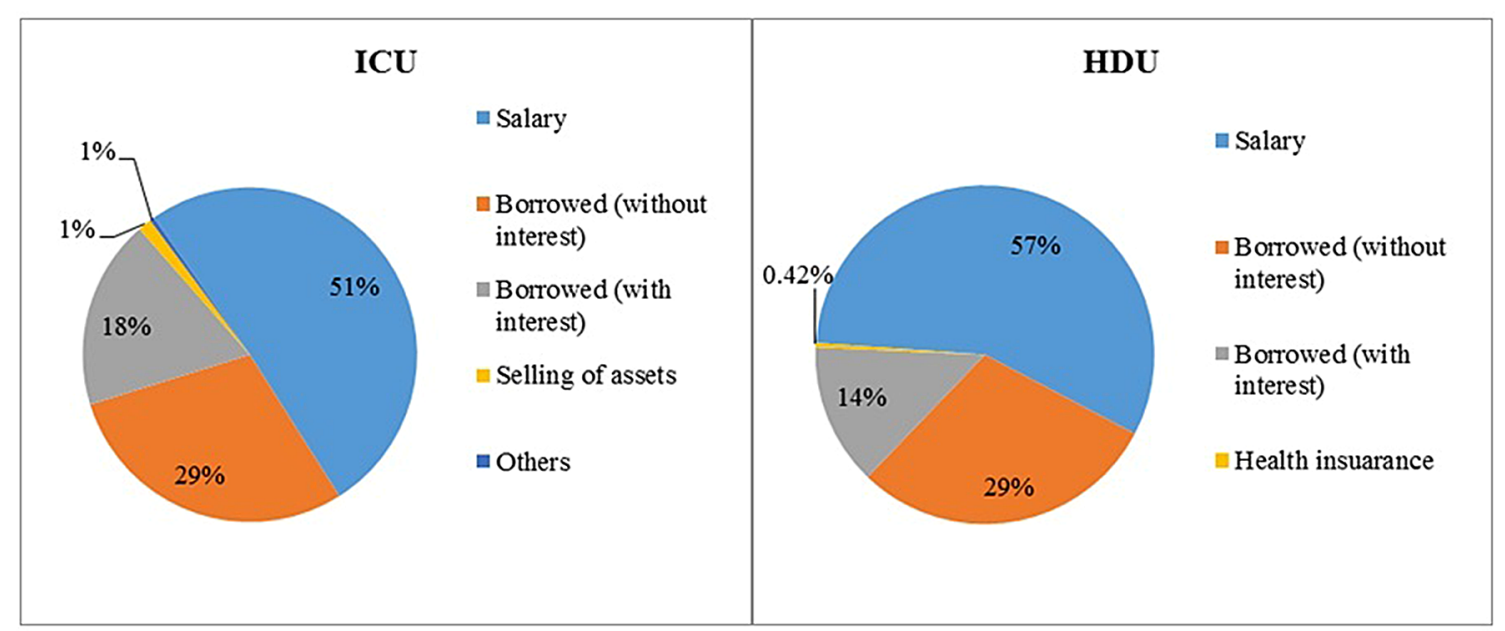

Fig. 2 Coping mechanisms (\%) for out-of-pocket expenditure for treatment of liver disorders in an intensive care unit in India. $H D U$ high dependency unit, $I C U$ intensive care unit

Table 4 Indirect costs for treatment of liver disorder patients in the intensive care unit of a tertiary care hospital in India

\begin{tabular}{lrll}
\hline Admission status & N & Mean US\$ (INR) & Standard error US\$ (INR) \\
\hline ICU & 65 & $166(9952)$ & $25.1(1507)$ \\
HDU & 85 & $182(10,903)$ & $21.7(1304)$ \\
Total & 150 & $175(10,491)$ & $16.4(984)$ \\
\hline
\end{tabular}

Conversion rate: $\$$ US $1=$ INR60

$H D U$ high dependency unit, ICU intensive care unit, INR Indian National Rupee, US\$ United States dollar

A study done in 2009 to assess the cost effectiveness of various policy options available for restricting alcohol consumption reported that educational and counselling programmes for alcohol users are not cost effective, whereas enforcing increased taxes on alcohol purchase and restrictions on alcohol sales are generally cost effective [48].

\subsection{Policy Implications: Treatment and Care}

The high cost of treating chronic liver disorders has twin challenges: firstly from patient perspective, wherein there are a large proportion of households who face CHE as a result of treatment. Any attempt at achieving universal health care will need to bring treatment of these chronic 
liver disorders into the benefit package. This brings us to the second fiscal challenge, which is for the payer or the health system to sustain the high cost of care. In view of the high cost of management of chronic liver disease, there is a need to identify more cost-effective approaches to management. For example, there are a range of drugs and newer molecules that are being used for treatment of HCVrelated cirrhosis. Whether or not these are cost effective should be assessed before any decision on commissioning these drugs for clinical use is taken.

Our study reveals that around $80 \%$ of the OOP expenditure for treatment of liver disorders in an ICU setting was spent on purchasing medicines. This depicts the low availability of medicines in public sector hospitals $[49,50]$, which inflicts a high burden of OOP expenditure for buying medicines, specifically among those who utilize the public sector hospitals, and exposes them to CHE [19, 22, 25]. Mere allocation of funds for free availability of medicines in public sector hospitals may not be enough; in fact, procurement systems should be evaluated frequently for better efficiency and making necessary reforms for better availability of medicines [50].

\subsection{Limitations}

First, we did not collect data on severity of disease or risk factors associated with disease at baseline, that is, at the time of admission. We identify this as a limitation in our study as this has some bearing on OOP expenditure for treatment. Second, estimates from our study may have limited generalizability due to several factors. Our study estimates are based on data from a single tertiary care public sector hospital. In India, to date, there is no provision for intensive care treatment at secondary level in the public sector, although these services are available with private tertiary care hospitals. Patients accessing these services from the deregulated private sector are susceptible to incurring high OOP expenditure. Third, while we followed up the patients until 6 months from discharge to collect data on post-hospitalization OOP expenditure, we could not collect health system cost data for patients utilizing the public sector for post-hospitalization care.

\section{Conclusion}

To conclude, our study findings point to significant economic costs related to treatment of liver disorders in a tertiary care setting in India. High OOP costs impose a financial challenge to the households, with near universal occurrence of CHE. The national strategy should focus of prevention of these liver disorders. At the same time, providing subsidized treatment through public sector hospitals or purchasing treatment through publicly financed healthcare insurance schemes should be considered. Strategies to reduce cost of care through application of cost-effective methods of treatment should be considered.

Acknowledgements We gratefully acknowledge the funding support received as part of Intramural Research Grant of the Post Graduate Institute of Medical Education and Research, Chandigarh, India.

Data Availability Statement Data on health system resources has been enclosed as a supplementary appendix. Patient level data analysed during the current study are available from the corresponding author on reasonable request. The corresponding author can be contacted via email: shankarprinja@gmail.com

Author Contributions Conceived the study: SP and YKC. Study design: SP, PB and MK. Study tools: SP and PB. Data collection: PB, SP and AD. Data analysis: PB and SP. Validation of estimates: SP, AD, YKC and MK. First draft: SP and PB. All authors reviewed and approved the final study draft.

\section{Compliance with Ethical Standards}

Funding The study was funded by the intramural Research Grant of Post Graduate Institute of Medical Education and Research, Chandigarh, India (http://pgimer.edu.in/PGIMER_PORTAL/ PGIMERPORTAL/home.jsp).

Ethical approval The study was approved by the Institute Ethics Committee of the Post Graduate Institute of Medical Education and Research, Chandigarh, India. Informed consent was taken from concerned persons at the time of data collection.

Conflict of interest Shankar Prinja, Pankaj Bahuguna, Ajay Duseja, Manmeet Kaur and Yogesh K. Chawla declare no conflict of interest.

Open Access This article is distributed under the terms of the Creative Commons Attribution-NonCommercial 4.0 International License (http://creativecommons.org/licenses/by-nc/4.0/), which permits any noncommercial use, distribution, and reproduction in any medium, provided you give appropriate credit to the original author(s) and the source, provide a link to the Creative Commons license, and indicate if changes were made.

\section{References}

1. Lozano R, Naghavi M, Foreman K, Lim S, Shibuya K, Aboyans $\mathrm{V}$, et al. Global and regional mortality from 235 causes of death for 20 age groups in 1990 and 2010: a systematic analysis for the Global Burden of Disease Study 2010. Lancet. 2012;380:2095-128.

2. Murray CJL, Vos T, Lozano R, Naghavi M, Flaxman AD, Michaud C, et al. Disability-adjusted life years (DALYs) for 291 diseases and injuries in 21 regions, 1990-2010: a systematic analysis for the Global Burden of Disease Study 2010. Lancet. 2012;380:2197-223.

3. Shrivastav A, Kumar S. Hepatitis in India: Burden, Strategies and Plans. Natl Centre Dis Control (NCDC) Newslett. 2014;3(1):1-5.

4. Ray G. Trends of chronic liver disease in a tertiary care referral hospital in eastern India. Indian $\mathbf{J}$ Public Health. 2014;58(3):186-94. 
5. Miniño AM, Xu J, Kochanek KD, Tejada-Vera B. Death in the United States. NCHS Data Brief. 2007;2009:1-8.

6. Buti M, San Miguel R, Brosa M, et al. Estimating the impact of hepatitis $\mathrm{C}$ virus therapy on future liver-related morbidity, mortality and costs related to chronic hepatitis C. J Hepatol. 2005;42:639-45.

7. Narang A, Kiran PS, Kumar P. Cost of neonatal intensive care in a tertiary care center. Indian Pediatr. 2005;42:989-97.

8. Prinja S, Jeet G, Verma R, Kumar D, Bahuguna P, Kaur M, et al. Economic analysis of delivering primary health care services through community health workers in 3 North Indian states. PLoS One. 2014;9(3):e91781.

9. Prinja S, Manchanda N, Mohan P, Gupta G, Sethy G, Sen A, et al. Cost of neonatal intensive care delivered through district level public hospitals in India. Indian Pediatr. 2013;50:765-72.

10. Prinja S, Mazumder S, Taneja S, Bahuguna $P$, Bhandari $P$, Mohan $\mathrm{P}$, et al. Cost of delivering child health care through community level health workers: how much does extra does IMNCI cost? J Trop Pediatr. 2013;59(6):489-95.

11. Sur D, Chatterjee S, Riewpaiboon A, Manna B, Kanungo S, Bhattacharya SK. Treatment cost for typhoid fever at two hospitals in Kolkata, India. Health Popul Nutr. 2009;27:725-32.

12. El Saadany S, Coyle D, Giulivi A, Afzal M. Economic burden of hepatitis $\mathrm{C}$ in Canada and the potential impact of prevention. Results from a disease model. Eur J Health Econ. 2005;6:159-65.

13. PGIMER. 47th Annual Report. Post Graduate Institute of Medical Education and Research, Chandigarh. 2013-2014.

14. Personal Communication. S.D. Sharma. Post Graduate Institute of Medical Education and Research (PGIMER), Chandigarh. 2014.

15. Drummond M, Sculpher M. Common methodological flaws in economic evaluations. Med Care. 2005;43:II-5--14.

16. The Economic Times: Forex rates. 2014. http://economictimes. indiatimes.com/markets/forex. Accessed 15 Feb 2015.

17. WHO. The world health report 2010-health systems financing: the path to universal coverage. Geneva: World Health Organization; 2010.

18. Osborn D, Cutter A, Ullah F. Universal sustainable development goals: understanding the transformational challenge for developed countries. Stakeholder Forum. 2015.

19. Prinja S, Gupta R, Bahuguna P, Sharma A, Aggarwal A, Phogat A, et al. A composite indicator to measure universal health care coverage in India: way forward for post-2015 health system performance monitoring framework. Health Policy Plan. 2016;32(1):43-56.

20. Saksena P, Smith T, Tediosi F. Inputs for universal health coverage: a methodological contribution to finding proxy indicators for financial hardship due to health expenditure. BMC Health Serv Res. 2014;14:577.

21. Wagstaff A. Measuring financial protection in health. The World Bank Development Research Group Human Development and Public Services Team. 2008. http://documents.worldbank.org/ curated/en/157391468140940134/pdf/wps4554.pdf. Accessed 20 May 2017.

22. Prinja S, Bahuguna P, Gupta R, Sharma A, Aggarwal A, Kumar R. Coverage and financial risk protection for institutional delivery: how universal is provision of maternal health care in India? PLoS One. 2015;10(9):e0137315.

23. Lensberg B, Drummond M, Danchenko N, Despiégel N, François C. Challenges in measuring and valuing productivity costs, and their relevance in mood disorders. ClinicoEcon Outcomes Res. 2013;5:565-73.

24. Zhang W, Bansback N, Anis A. Measuring and valuing productivity loss due to poor health: a critical review. Soc Sci Med. 2010;72:185-92.
25. Prinja S, Aggarwal A, Kumar R, Kanavos P. User charges in health care: evidence of effect on service utilization \& equity from north India. Indian J Med Res. 2012;136(5):868-76.

26. Prinja S, Kanavos P, Kumar R. Health care inequities in north India: role of public sector in universalizing health care. Indian $\mathrm{J}$ Med Res. 2012;136(3):421-31.

27. Jain M, Mukherjee K. Economic burden of breast cancer to the households in Punjab, India. Int $\mathrm{J}$ Med Public Health. 2016;6:13-8.

28. Jan S, Lee SW-L, Sawhney JP, Ong TK, Chin CT, Kim H-S, et al. Catastrophic health expenditure on acute coronary events in Asia: a prospective study. Bull World Health Organ. 2016;94:193-200.

29. Prinja S, Chauhan AK, Karan A, Kaur G, Kumar R. Impact of publicly financed health insurance schemes on healthcare utilization and financial risk protection in India: a systematic review. PLoS One. 2017;12(2):e0170996.

30. Planning Commission of India. High level expert group report on universal health coverage for India. New Delhi: Planning Commission of India; 2011.

31. Selvaraj S, Karan AK. Why publicly-financed health insurance schemes are ineffective in providing financial risk protection. Econ Political Weekly. 2012;XIVII:11.

32. Mehta SH, Vogt SL, Srikrishnan AK, Vasudevan CK, Murugavel $\mathrm{KG}$, Saravanan S, et al. Epidemiology of hepatitis C virus infection \& liver disease among injection drug users (IDUs) in Chennai, India. Indian J Med Res. 2010;132:706-14.

33. Suthar H, Suthar K, Mewada B. Clinical profile of cases of alcoholic liver disease. Int $\mathbf{J}$ Med Sci Public Health. 2013;2(2):408-12.

34. Edmunds WJ. Universal or selective immunisation against hepatitis B virus in the United Kingdom? A review of recent costeffectiveness studies. Commun Dis Public Health. 1998;1:221-8.

35. Gupta M, Prinja S, Kaur M, Kumar R. Cost effectiveness of Hib vaccine for introduction in national immunization schedule in Haryana state, India. Health Policy Plan. 2013;28(1):51-61.

36. Chowdhury M, Ahmed A, Kalim N, Koblinsky M. Causes of maternal mortality decline in Matlab, Bangladesh. J Health Popul Nutr. 2009;27(2):108-23.

37. Gupta SK, Sosler S, Lahariya C. Introduction of haemophilus influenzae type b (Hib) as pentavalent (DPT-HepB-Hib) vaccine in two states of India. Indian Pediatr. 2012;49:707-9.

38. Sharma A, Kaplan WA, Chokshi M, Farooqui HH, Zodpey SP. Implications of private sector Hib vaccine coverage for the introduction of public sector Hib-containing pentavalent vaccine in India: evidence from retrospective time series data. BMJ Open. 2015;5:e007038.

39. Van Herck K, Vorsters A, Van Damme P. Prevention of viral hepatitis (B and C) reassessed. Best Pract Res Clin Gastroenterol. 2008;22:1009-29.

40. Schmunis GA, Rodriguez G, Coenen J, Bellorin EG, Gianella A. Prevention of blood-borne diseases in Bolivia, 1993-2002. Am J Trop Med Hyg. 2008;79:803-8.

41. Chelleng PK, Borkakoty BJ, Chetia M, Das HK, Mahanta J. Risk of hepatitis $\mathrm{C}$ infection among injection drug users in Mizoram, India. Indian J Med Res. 2008;128(5):640-6.

42. Armstrong G, Kermode M, Sharma C, Langkham B, Crofts N. Opioid substitution therapy in Manipur and Nagaland, north-east India: operational research in action. Harm Reduct J. 2010;7:29.

43. Connock M, Juarez-Garcia A, Jowett S, Frew E, Liu Z, Taylor $\mathrm{RJ}$, et al. Methadone and buprenorphine for the management of opioid dependence: a systematic review and economic evaluation. Health Technol Assess. 2007;11:1-171.

44. Mann RE, Smart RG, Rush BR, Zalcman RF, Suurvali H. Cirrhosis mortality in Ontario: effects of alcohol consumption and Alcoholics Anonymous participation. Addiction. 2005;100:1669-79. 
45. Ramstedt M. Population drinking and liver cirrhosis mortality: is there a link in Eastern Europe? Addiction. 2007;102:1212-23.

46. Smart RG, Mann RE, Suurvali H. Changes in liver cirrhosis death rates in different countries in relation to per capita alcohol consumption and Alcoholics Anonymous membership. J Stud Alcohol. 1998;59:245-9.

47. Norström T, Ramstedt M. Mortality and population drinking: a review of the literature. Drug Alcohol Rev. 2005;24:537-47.

48. Anderson P, Chisholm D, Fuhr DC. Effectiveness and cost-effectiveness of policies and programmes to reduce the harm caused by alcohol. Lancet. 2009;373:2234-46.
49. GOI. Key indicators of social consumption in india health. NSS 71st Round. Jan-Jun 2014. National Sample Survey Office. Ministry of Statistics and Program Implementation. Government of India. 2015.

50. Prinja S, Bahuguna P, Tripathy J, Kumar R. Availability of medicines in public sector health facilities of two North Indian States. BMC Pharmacol Toxicol. 2015;16:43. 